\title{
Usos de la violencia en el cine de Amat Escalante
}

Uses of Violence in the cinema of Amat Escalante

Juan Carlos Reyes-Vázquez *

* Universidad de las Américas Puebla, México

Correo-e: jreyesvazquez@yahoo. com.mx

Recibido: 7 de julio de 2020 Aprobado: 6 de abril de 2021
Resumen: Se analizan, desde paralajes específicos, los usos de la violencia en la filmografía del mexicano Amat Escalante. Al recurrir al término 'usos' nos referimos a dos preguntas en particular: con qué objetivos y de qué manera estético-visual utiliza el director estas representaciones de lo violento. Para ello, profundizamos en sus cuatro largometrajes hasta ahora estrenados: Sangre (2005), Los bastardos (2008), Heli (2013) y La región salvaje (2016). De acuerdo con lo expuesto por Slavoj Žižek en el libro Sobre la violencia. Seis reflexiones marginales, planteamos que Escalante hace uso de la violencia en pantalla en tres sentidos: narrativo, estético y poético (éste último, referido a la relación político-afectiva que se da entre las cintas y sus espectadores).

Palabras clave: arte contemporáneo; cine; director de cine; festival de cine; película; violencia; narcotráfico; México

Abstract: The uses of violence in the filmography of the Mexican Amat Escalante are analyzed from specific parallaxes. By resorting to the term 'uses' we refer to two questions in particular: with what objectives and in what aesthetic-visual way does the director use these representations of violence. To do this, we delve into his four feature films released so far: Blood [Sangre] (2005), The bastards [Los bastardos] (2008), Heli (2013) and The wild region [La región salvaje] (2016). According to what is stated by Slavoj Žižek in the book On violence. Six marginal reflections, we propose that Escalante makes use of violence on the screen in three senses: narrative, aesthetic and poetic (the latter, referring to the political-affective relationship that occurs between the films and their viewers).

Keywords: contemporary art; cinema; film maker; film festivals; film; violence; drug traffic; Mexico 
$\mathrm{E}$ 1 cine mexicano contemporáneo tiene entre sus temas recurrentes la violencia, detonada, en parte, por la llamada guerra contra el narcotráfico que implementó el Estado desde hace cerca de diez años con la intención de 'acabar' con el trasiego y venta de estupefacientes dentro del territorio nacional. Por supuesto, esta violencia representada en la pantalla tiene sus más claros antecedentes fílmicos en el cine de narcotraficantes y criminales, que directores como Mario Almada, Fernando Almada y Valentín Trujillo realizaron desde inicios de la década de los setenta hasta mediados de los noventa del siglo pasado.

Parece evidente que las causas de la violencia son complejas y no obedecen a una única variable, como la anteriormente mencionada guerra contra el narcotráfico. Sus móviles económicos, políticos y sociológicos son bastantes y su análisis requiere seriedad y profundidad. Las consecuencias de esta violencia y sus representaciones son multiformes, pero mucha de la que es mostrada por el cine guarda relaciones, aunque sea tangenciales, con el desgaste del tejido social que ha traído consigo la militarización de ciertas zonas del país, el desgobierno y el deterioro policial generado por la inseguridad. No es este el espacio adecuado para juzgar si dicha estrategia fue o es efectiva, o sus implicaciones geopolíticas, socioculturales y económicas. El asunto, sin duda, constituye un complejo rompecabezas del que es casi imposible comprender a totalidad sus piezas, o siquiera vislumbrar si éstas forman alguna imagen inteligible al ensamblarse. Es innegable que el tema no ha sido ajeno al cine mexicano en otros momentos de su historia; pero para el corpus de análisis de este artículo establecemos un periodo específico que, a su vez, remite a la obra de un cineasta cuyo trabajo comenzó hace dieciocho años.

Cuando hago referencia a los 'usos de la violencia' en la imagen cinematográfica, apunto a 'representaciones' de la misma en el cine. Por un lado, hablo de cine de ficción y, por otro, de un concepto de violencia que a su vez se compone desde muy diversos paralajes. Es evidente que las representaciones en los medios de comunicación, cualesquiera que sean, tienen una incidencia en las sociedades que las reciben, ya que legitiman, afianzan o rechazan hábitos, patrones de comportamiento o, en otros casos, una construcción ideológica.

La intención de este texto es argumentar que Amat Escalante (Barcelona 1979), en sus cuatro largometrajes hasta ahora estrenados, Sangre (2005), Los bastardos (2008), Heli (2013) y La región salvaje (2016), emplea imágenes violentas - ya sea de manera explícita o implícita- con tres intenciones específicas: como instrumento narrativo, como exploración estético-visual y como una poética sobre la relación político-afectiva que ocurre entre las cintas y sus espectadores.

Uno de los principales aspectos por los que un análisis como éste es relevante responde a que considero que parte de la crítica ha catalogado de violenta la obra de Escalante sin argumentos suficientemente sólidos, es decir, sin tomar en cuenta variables tan importantes como el contexto en el que se realiza dicho cine o las diversas interpretaciones a las que está sujeto un mismo filme. Con esto no planteo que dichas películas carecen de un componente violento o que todas son estética o dramáticamente inmejorables, sino que se han analizado de manera tangencial o unidimensional, mucho más aún por la crítica que por la academia. De la misma manera, me parece que se ha dejado de lado que el director ha logrado construir una visión cinematográfica sugestiva y compleja de nuestro país y algunas de sus problemáticas más profundas, pero sin la intención de ser moralizante o estérilmente crítico.

Con un juicio razonado que, como el de casi cualquiera que se dedique al ámbito las humanidades, no puede alejarse de la subjetividad, diría que los directores Amat Escalante, Carlos Reygadas, Gerardo Naranjo, Tatiana Huezo, Julio 
Hernández Cordón, Aarón Fernández, María José Cuevas y Natalia Beristáin forman un grupo vital dentro del cine mexicano contemporáneo.

Es cierto que las películas de Escalante no son éxitos de taquilla y no figuran entre las más 'populares', pero juzgar la calidad de su producción artística por variables como esas me parece corto de vista. Incluso, se ha dicho que únicamente hace 'cine para festival'. Sin embargo, cuando afirmo que es un creador relevante para el cine mexicano me refiero a que encuentro en sus cintas una poética, una búsqueda por construir un proyecto - para festival o no- arriesgado, sensible y cuya intención es problematizar y poner en duda saberes y sentires afianzados a lo largo de los años por los medios de comunicación de nuestro país.

Antes de proseguir, es pertinente puntualizar qué definición de violencia utilizo al recurrir a un concepto tan semánticamente intrincado. El término puede ser entendido de manera llana como una cualidad de lo violento o como el efecto de violentar algo o a alguien, pero la definición, o definiciones, con las que trabajo aquí son las propuestas en el libro Sobre la violencia. Seis reflexiones marginales, de Slavoj Žižek. El filósofo esloveno propone tres tipos de violencia, pero deja claro que no las entiende como acontecimientos separados, sino como ligeras variantes de un mismo evento ${ }^{1}$ y estado que se complementan o traslapan: una violencia subjetiva, una simbólica y otra sistémica. A decir de Žižek, la subjetiva es "directamente visible, practicada por un agente que podemos identificar al instante" (2009: 9); la simbólica se encuentra:

encarnada en el lenguaje y sus formas, la que Heidegger llama nuestra 'casa del ser', [...] casos de provocación de relaciones de dominación social reproducidas en nuestras formas de discurso habituales: todavía hay una forma

1 Žižek, en otro texto titulado Acontecimiento (2014), afirma que emplea el término para definir un momento de ruptura en el transitar de un evento a otro de mayor envergadura. más primaria de violencia, que está relacionada con el lenguaje como tal, con su imposición de cierto universo de sentido (2009: 10).

Y, por último, la sistémica, que implica "las consecuencias a menudo catastróficas del funcionamiento homogéneo de nuestros sistemas económico y político" (2009: 10). Como más adelante desarrollamos, en las películas analizadas aparecen de forma muy clara estos tres tipos de violencia, pero mi intención no es identificar o localizar escenas o momentos específicos que puedan ir ejemplificando o que correspondan exactamente con las definiciones anteriores, sino proponer que la violencia como acontecimiento, y posteriormente como dispositivo, es empleada por Escalante de las maneras antes anotadas: narrativamente, como una estética visual y como una poética sobre la relación político-afectiva entre las cintas y sus espectadores.

Es importante notar que este tipo de representación de la violencia no constituye una narración cabal de las situaciones, lo que Wallace Stevens llamaba 'descripción deslocalizada', propia del arte, sino que se trata de:

una descripción que crea, como trasfondo del fenómeno que describe, un espacio (virtual) propio inexistente de modo que lo que aparece en él no es una apariencia sostenida por la profundidad de una realidad, sino una apariencia descontextualizada, una apariencia que coincide plenamente con el ser real (Žižek, 2009: 14-15).

Lo que podemos obtener de lo propuesto por Žižek es que la violencia, unificando las tres definiciones que él apunta, funciona como un dispositivo, en el sentido que Giorgio Agamben reconstruye el término:

Lo que trato de identificar con este término [violencia] es ante todo un conjunto absolutamente heterogéneo que incluye discursos, 
instituciones, estructuras arquitectónicas, decisiones regulativas, leyes, medidas administrativas [...] tanto lo dicho como lo no dicho, he ahí los elementos del dispositivo (2006: 10).

Es decir, si bien sugiero que Escalante utiliza la violencia de manera narrativa, estética y política, bien valdría decir que lo hace, en términos generales, como un dispositivo, según lo anotado.

Sobre la propuesta cinematográfica del director, y a manera de contraste, Rafael Paz afirma en su crítica a Heli, publicada en la revista Forbes México, que "la violencia mostrada a cuadro [en los filmes de Escalante] recuerda a algunos trabajos de Michael Haneke, pero a diferencia del cineasta alemán, el mexicano logra generar empatía hacia sus personajes" (2013: s/n). Por otro lado, Manohla Dargis, emblemática crítica de The New York Times, declara que "Heli, [es] una de esas películas de explotación que entregan su violencia envuelta en pretensiones de arte" (2013: s/n). No es mi intención dilucidar aquí qué tan válidas, necesarias o logradas son las representaciones de la violencia en las cintas de Escalante, sino con qué intenciones aparecen en pantalla. Ante una exposición como ésta, me parece que la crítica se pierde entre las líneas, frases hechas y lugares comunes. Considero que Heli no es un filme de explotación, en el sentido que los Film Studies entienden de una película con esos intereses y cualidades estéticas de realización y, por otro lado, Escalante hace un retrato de la problemática que aqueja a ciertas comunidades del país de una manera puntual y sin tapujos, en un modo distinto a como otros directores lo han intentado, por ejemplo, Luis Estrada en El infierno (2010), parodia con escenas violentas como las de Heli, pero en donde el género cómico-satírico maquilla lo 'incómodo'.

A manera de breve sinopsis de los largometrajes que componen el corpus de este texto, Sangre, selección oficial en el Festival de Cannes, versa sobre la trivial vida de Diego y Blanca, una pareja que vive una anodina relación marital que discurre entre ver telenovelas, trabajar y discutir. Blanca es una mujer celosa que pasa constantemente de la agresión al arrepentimiento, irascible de forma notable cuando duda de la fidelidad de su marido, aunque después busca recompensar al timorato ofendido con relaciones sexuales a las que él nunca se niega. En un hilo argumental paralelo, cuestionable, desde mi perspectiva, en sentido dramático, nos enteramos de que Diego tiene una hija adolescente de un matrimonio anterior, la cual aparece en escena sólo para morir y darle un motivo de redención al personaje principal. Los bastardos, nominada en el Festival de Cannes y ganadora del Festival Internacional de Cine de Morelia, cuenta la historia de Jesús y Fausto, dos migrantes jornaleros provenientes de Guanajuato que buscan sobrevivir en Los Ángeles. Como en otros filmes del director, en LoS bastardos encontramos un evento que resume la carga dramática de la cinta, pero que se va desenvolviendo conforme ésta avanza. Con el despliegue de la trama, descubrimos que 'alguien' les ha dado una escopeta a los protagonistas y ha pagado para que allanen la casa de una mujer - aparentemente, la exesposa del individuo que les ha entregado el arma-y la asesinen. Jesús es parco y nunca muestra alguna especie de remordimiento hasta que se ha consumado el homicidio, mientras que Fausto, un hombre más joven, que muestra cierta reticencia y de quien escuchamos hasta una propuesta de abandonar el trabajo encargado, es quien finalmente jala el gatillo, pero también quien logra escapar a salvo de la casa. Esta película, cinematográficamente más lograda que Sangre, muestra con mucha claridad los diversos tipos de violencia que anteriormente he mencionado. Heli, película con la que Escalante obtuvo el premio a mejor director en el Festival de Cannes de 2013, así como una nominación a la Palme d'Or, cuenta la historia de Heli, un joven que vive con su esposa, su pequeña hija, su padre y su hermana en un pueblo de Guanajuato - lugar en el que también se ubica el universo narrativo de La región salvaje-. La cinta 
cuenta el estrepitoso camino, descenso y pérdida de una familia al cruzarse su destino, de manera casi accidental, con el 'ejército-narcotráfico' y la 'corrupción-burocracia'. Finalmente, La región salvaje es la historia de una criatura extraterrestre que llega a la Tierra en un meteorito. Custodiada por una pareja de ancianos científicos que viven en una recluida cabaña en el bosque, se manifiesta como una especie de organismo tentacular capaz de provocar el placer sexual y el deseo más absoluto e inimaginable, y, al mismo tiempo, una violencia que no conoce límites. Después de varios encuentros con la criatura, ésta lastima a Verónica, quien tiene que acudir a un hospital en el que conoce a Fabián, enfermero y hermano de Alejandra, la cual está casada con un violento, puritano y falaz Ángel. El drama se complica cuando Verónica lleva a Fabián y después a Alejandra con la criatura.

En cuanto al uso narrativo de la violencia, Aleksandra Jablonska afirma que en un cine como el de Amat Escalante se presenta "un mundo que se manifiesta en la vida cotidiana de los personajes como limitado, opresor, falto de elementos a partir de los cuales podría construirse una existencia más feliz" (2007: 62). Esto, sin duda, lo podemos comprobar en los cuatro largometrajes mencionados, ya que muestran un universo lleno de individuos sin posibilidad de estructurar una narrativa vital, suspendidos en un impase que le permite al director contar un evento de su existencia sin que mucho más pase alrededor. Lo anterior se hace aún más evidente cuando notamos que en las películas de Escalante el pasado de los personajes rara vez aparece en pantalla. Si bien es cierto que en algunos casos se muestran pequeños guiños a esos acontecimientos olvidados, nunca constituyen temas centrales de la trama.

En Heli, la primera escena ya es violenta: una bota presiona con fuerza las caras ensangrentadas de individuos anónimos en la batea de una camioneta que los lleva hacia un puente peatonal del que posteriormente cuelgan a uno de ellos. Escalante hace uso también de espacios vacíos que el espectador tiene que llenar, como en cualquier obra, pero en este caso es necesario para que la historia avance. Por ejemplo, nunca vemos alguna escena de la violación de la hermana pequeña de Heli, pero la claridad y crudeza con que es presentada por su propia ausencia es abrumadora. El director utiliza también la violencia como un recurso narrativo al intentar contar el papel que el gobierno juega en la eufemísticamente llamada guerra contra las drogas o en los pesares burocráticos que la familia tiene que sobrellevar para intentar resolver la tragedia que los ha sobrecogido. Me parece que Escalante, al menos en las cuatro películas de las que aquí hablo, no sólo retrata la violencia ejercida sobre una masa, un país, un 'todos', sino que también, en buena medida, decide contar las historias de individuos particularmente elegidos, tragados por el vórtice de un huracán al que apenas ven pasar en forma de un desafortunado y único acontecimiento.

Sangre tiene un tono diferente, que podríamos identificar como el de un director que está comenzando a experimentar con su propia poética. La película cuenta con tomas sumamente largas que obstaculizan el pulso dramático, pero que parecen servirle a Escalante como el 'ensayo' de un recurso parecido utilizado de manera sobresaliente en Heli. En Sangre, la narración no estaría completa sin las escenas en las que Blanca agrede a Diego, ya que deja clara la implicación de lo cotidiano en el desarrollo argumental. Del mismo modo, la aparición y muerte, aparentemente violenta, de la hija de Diego, resulta necesaria para que la trama avance hacia el lugar en el que el director desea ubicar a su personaje principal: una epifanía casi metafísica en la que se redime de 'pecados' que nunca son mostrados.

En Los bastardos, de nueva cuenta aparece un evento escondido en un relato in medias res que permite que los acontecimientos progresen con cierta incertidumbre. El mencionado encargo del asesinato de una mujer es parte del interrogante 
activo que logra que la película avance. Sin la violencia que sufren los dos migrantes, personajes principales de la historia, así como la que ellos ejercen sobre otros — rasgos casi incidentales, cuando no accidentales-, la cinta no tendría un pulso constante. La migración 'forzada' de estos individuos constituye el primer acto de violencia, aunque se desarrolle detrás de la pantalla. El énfasis que se pone en este punto es más que un simple apunte y logra que la narración tome forma, pues se convierte en la punta del iceberg de la historia de violencia sistémica que padecen los migrantes. Esto, consideramos, en buena medida ocurre debido a lo que Philip Zimbardo llama, en su libro El efecto Lucifer, 'desconexión moral por deshumanización'. Dice el autor:

La deshumanización aparece siempre que un ser humano considera que se debe excluir a otro ser humano de la categoría moral de persona. Los objetos de este proceso psicológico pierden su condición humana a los ojos de quienes suspenden la moralidad que normalmente regiría sus actos hacia sus congéneres. La deshumanización es un proceso básico en el prejuicio, el racismo y la discriminación (Zimbardo, 2018: 404).

Algo parecido ocurre con el asesinato de la mujer - escena violenta por excelencia en el filme-, catalizador narrativo que nos lleva al final de la cinta, pero que ocurre por la absoluta ofuscación de uno de los personajes. De manera específica, considero que en Los bastardos el director construye, desde esa dicotomía que la frontera establece, dos dualidades evidentes. En primer lugar, una clara mezcla entre aquello que entendemos como una frontera física y una metafórica; y, segundo, un 'afuera' que se impone a un 'adentro' con el que los personajes tienen que lidiar durante toda la película y en el que la violencia se hace más visible.

Por otro lado, en La región salvaje Escalante muestra un tipo de violencia muy peculiar, que se encuentra en diferentes niveles: en el deseo y su contraposición (por ejemplo, encontramos atisbos de las relaciones sexuales que la criatura tiene con sus diferentes 'amantes', así como varias escenas de las agresiones físicas de Ángel hacia su esposa y cuñado, con un claro corte naturalista) y, por supuesto, la homofobia y el machismo de los que somos testigos a lo largo de la cinta, violencia sistémica que precede los eventos narrados, pero que les otorga un marco referencial, tanto espaciotemporal como simbólico.

Ahora, cuando hablamos de un uso estético-visual, me refiero específicamente al tratamiento que el director da a la imagen violenta como parte de su estilo artístico. En este caso, nos podríamos referir a la violencia subjetiva propuesta por Žižek, que es muy física. Por ejemplo, Gérard Imbert, en su texto "La nueva carne: el cuerpo entre la carencia y el exceso en el cine actual”, afirma que en las imágenes de Heli el cuerpo es violentado en sus partes más sensibles. Mientras dos hombres son torturados, unos adolescentes juegan con su videoconsola y no prestan importancia al otro 'espectáculo' no mediado que se desarrolla frente a ellos. Ese nuevo código violento se ha incorporado al modus vivendi:

\footnotetext{
Llama la atención la espectacularización de la violencia por los narcotraficantes, con la exposición a la mirada pública de las cabezas cortadas de los traidores, colgando de un puente, para infundir miedo y, al mismo tiempo, crear insensibilidad. La violencia está inscrita en los cuerpos, se ha banalizado (2014:69)
}

Pienso que esa naturalidad y banalización se identifica no sólo en las escenas y en el mismo guion de Heli, sino en el contexto social (real) en el que se basa la película. Es decir, la representación tan explícita de la violencia en las obras de Escalante es, para muchos, exagerada, aunque cosas peores ocurren a diario a lo largo y ancho de todo el territorio nacional. A Imbert le llama la atención esa espectacularización, que 
considera excesiva, pero pareciera que por eso mismo pierde de vista que esa violencia certifica simbólicamente las situaciones reales del México contemporáneo, mucho más porque se ejerce sobre personajes que han entrado a dicha dinámica casi por error. Es por ello que no debemos confundir la estética casi documental del director con una innegable intención de hacer de Heli casi un cuadro costumbrista de la violencia actual efectuada indiscriminadamente por narcotraficantes, soldados y gobierno.

Otro uso estético-visual de la violencia lo encuentro en Los bastardos, cuando los protagonistas se encuentran con una familia en un pícnic en el que dos individuos se golpean brutalmente, en las tomas en las que apuntan con la escopeta y se 'esconden' detrás de ella, en los encuadres estáticos en los que violentan sexualmente a la mujer a cuya casa han entrado con intención de matarla, y en el plano en el que literalmente le vuelan la cabeza momentos antes de que entre su hijo por la puerta. Así, somos testigos de un marco iluminado por el que vemos al hijo tomar un refresco, mientras que en el centro del cuadro se distingue un cuerpo sin cabeza y una pared manchada de restos óseos, encefálicos y sangre. La puerta constituye una frontera entre el horror de la violencia y la vida cotidiana, la cual existe para el joven y su madre con su vida en los suburbios de Los Ángeles, pero no para Jesús y Fausto, quienes ocupan un mismo espacio iluminado en el que lo trágico y la normalidad se mezclan. Como puntualmente anota De León: "en [...] Los bastardos (2008) el cineasta Amat Escalante aborda el tema de la frontera justo como ese encuentro violento de culturas y el cómo afectan ya no la totalidad del panorama, sino sus expresiones más mínimas, más personales" (2012: 54).

De Heli habría que decir que posiblemente es la cinta que más imágenes violentas emplea como un recurso estético-visual por medio del cual el director explora las posibilidades expresivas del cine. Recordemos, por ejemplo, la cabeza del individuo con la cara ensangrentada que es pisada por una bota de tipo militar, el encuadre en el que un hombre cuelga muerto de un puente, y la camioneta del ejercito amedrentando a Heli en la puerta de su casa. O también la secuencia en la que varios sujetos golpean al protagonista y al soldado que ha robado cocaína resguardada por el propio ejército, misma que tiene como fondo a unos niños que se entretienen con una consola. Segundos después, uno de los pequeños repite los golpes que antes ejecutara en el videojuego, pero ahora sobre las personas torturadas fuera de la pantalla. Un último ejemplo es la búsqueda y muerte del violador de la hermana de Heli. El cuadro final, un Extreme Long Shot, muestra al protagonista asesinando a un hombre; la distancia, el encuadre y la paleta de color no sólo refuerzan la violencia de la toma, sino que la suspenden en el imaginario del espectador.

Finalmente, considero que esa lógica de representación de la violencia en pantalla es un posicionamiento político, en el sentido más complejo del término, así como una postura sobre la afectividad que busca el director en sus espectadores. Se dice que estas películas tienen un impacto en su audiencia por ser violentas, pero se omite que, por el contrario, si hay un ejercicio de performatividad en el público se debe en gran medida a que nos 'recuerda' la violencia. Como apunta Patricia Torres San Martín, sin duda, el cine contribuye "a la formación de adscripciones de identidad vinculadas directamente a maneras de entender el mundo, construidas a partir de configuraciones estéticas y de conocimiento" (2008: 97). En las obras de Escalante, la violencia sobre el cuerpo es de las más importantes y con la que es más fácil para el espectador relacionarse. Imbert plantea:

tal vez sea a través del cuerpo como mejor se expresa el mal-estar contemporáneo. El cuerpo funciona entonces como síntoma, traducción 
de las huellas del inconsciente en el sujeto, de lo que se le escapa, de lo que huye del control de la mente (2008: 63).

Pareciera que hoy en día es necesario corporeizar las agresiones para que se les preste suficiente atención: mientras no haya manifestación física — subjetiva, diría Žižek - podría no percibirse como un tipo de violencia. Especialmente, en Heli y Los Bastardos - aunque en La región salvaje el deseo muestra dos caras de un fenómeno desconcertante - el cuerpo es el "maniquí de toda una sociedad violenta por violentada" (Torres San Martín, 2008: 71). La misma autora anota:

\begin{abstract}
Si bien tenemos la certeza de que frente a una película predominan las capacidades perceptivas y emotivas de los sujetos-audiencia, no podemos aislar el contexto personal, social y cultural en el que se encuentran inscritas y del cual se desprende una serie de factores que al final del proceso influirán en la lectura y resignificación de la misma (Torres San Martín, 2008: 71).
\end{abstract}

Este asunto cobra relevancia cuando observamos que en dichas cintas no sólo es importante percatarse de lo violento en uno o varios personajes, sino en un entorno al que está encadenada, algo que Zimbardo cataloga como procesos situacionales y sistémicos, con lo que define el enfoque situacional de la violencia (2018: 533-534). Tal vez si ésta no estuviera en todas las estructuras que los rodean, él/ellos/ellas no serían violentados como individuos y, por tanto, su comportamiento sería distinto. La audiencia no siempre está dispuesta a afrontar este tipo de cuestionamiento que disloca el visionado. El uso políticoafectivo de la violencia es mucho más evidente en Los bastardos y Heli, ya que hacen clara referencia a la migración hacia los Estados Unidos y la pobreza que impera en gran parte del país. Como expone Umberto Eco: "[Tenemos una] tendencia a entender lo que nos sucede en términos de lo que Barthes llamaba un texte lisible. Puesto que la ficción narrativa parece más confortable que la realidad, intentamos interpretar esta última como si fuera ficción narrativa" (1997: 132).

Por ello, me parece relevante subrayar que cuando hablamos de violencia en estos filmes es imposible no apuntar a un acto social y político. Dice Imbert:

\begin{abstract}
La violencia - o las violencias - no pueden ser tomadas aisladamente. La violencia no es un hecho puntual, aislado [...] La violencia es un hecho social que en este caso se ve retratado de ciertas maneras y con intenciones puntuales por un director que apuesta por un cine no convencional que aborda temáticas en donde la violencia aparece como todo un conjunto de mecanismos sociales: cotidiana, organizada, desorganizada, física, sistémica, pero nunca como un fenómeno aislado (Gérard Imbert, en Zamorano Rojas, 2013: 266).
\end{abstract}

Si pensamos en la manera en que la violencia se inserta en los individuos de una sociedad, podríamos recordar lo que Aleksandra Jablonska apunta en su texto "Identidades en redefinición: Los procesos interculturales en el cine mexicano contemporáneo", cuando afirma que quienes migran se llegan a caracterizar, de una manera no definitiva pero sí general, como 'sujetos liminales', es decir, individuos que han abandonado lo que conocían como su más habitual forma de vida 'anterior al viaje', con sus valores, reglas y economías morales. El problema para las personas desplazadas, y ahora liminales, es que no siempre logran ingresar a una nueva estructura social, por lo que no obtienen un lugar en dicho orden y, por lo tanto, la misma sociedad los mantiene al margen (2007: 59).

Es entonces con estos usos de la violencia que el director concreta la búsqueda de un diálogo con la audiencia. Escalante no recurre de manera infundada a esas representaciones, sino que, en cierta medida, las emplea como un pacto 
incómodo con el espectador. Como es de esperarse, coexisten posiciones encontradas al respecto y algunos críticos catalogan de banal o efectista esta intención de confrontar al público. Para López Mejía,

esta mezcla de situaciones y escenas ilógicas, extrañas, enervantes, no sólo caracterizará su obra, sino que será una de las principales razones de la incomodidad que sus cintas provocan en el espectador promedio y del encanto con que atrapan a la crítica y a los jurados de festivales (2012: 141).

La capacidad visual y sonora que Escalante despliega en su cine muestra su claro dominio del oficio. Si bien algunos lo han catalogado como un director efectista, es decir, que intenta forzar las emociones de la audiencia, o, en otros casos, gratuitamente violento, me parece que dichos juicios no observan su capacidad de representar, que no retratar, lugares sumamente complejos de una realidad que no sólo implica a los ciudadanos de un país, ya que los temas que sus películas abordan se vuelven localizables en un espectro de disputa simbólica de mucho mayor alcance.

\section{REFERENCIAS}

Agamben, Giorgio (2006), ¿Qué es un dispositivo?, Madrid, Anagrama.

Dargis, Manohla (2013), "Ducking Rain and Competition at Cannes", en The New York Times, 17 de mayo de 2013, Nueva York.

De León, Francisco (2012), "Cuando afuera sólo cabe adentro", en Claudia Curiel de Icaza y Abel Muñoz Hénonin, Reflexiones sobre cine mexicano contemporáneo. Ficción, México, Cineteca Nacional.

Eco, Umberto (1997), Seis paseos por los bosques narrativos, Barcelona, Lumen.

Imbert, Gérard (2014), "La nueva carne: el cuerpo entre la carencia y el exceso en el cine actual”, Opción, vol. 30, núm. 74, pp. 60-73.
Escalante, Amat (dir.) (2005), Sangre, cinta cinematográfica, México/Francia, Ad Vitam Productions, Mantarraya Producciones, Tres tunas, No Dream Cinema, Estudios Churubusco Azteca.

Escalante, Amat (dir.) (2008), Los bastardos, México/Francia, Mantarraya Producciones, Tres Tunas, No Dream Cinema, See more.

Escalante, Amat (dir.) (2013), Heli, México/Francia, Mantarraya Producciones, Tres tunas, Le Pacte, Foprocine, Unafilm, Lemming Film, Ticomán, IKE Asistencia.

Escalante, Amat (dir.) (2016), La región salvaje, México, Dinamarca, Francia, Alemania, Mantarraya Producciones/ Tres Tunas.

Estrada, Luis (dir.) (2010), El infierno, cinta cinematográfica, México, Bandidos Films, IMCINE, Foprocine, Estudios Churubusco Azteca, Eficine 226, Gobierno del Distrito Federal, Fonca.

Jablonska, Aleksandra (2007), "Identidades en redefinición: Los procesos interculturales en el cine mexicano contemporáneo", Estudios Sobre las Culturas Contemporáneas, época II, vol. XIII, núm. 26, pp. 47-76.

López Mejía, Sergio Raúl (2012), “Amat Escalante: La fanfarria para el hombre común”, en Claudia Curiel de Icaza y Abel Muñoz Hénonin, Reflexiones sobre cine mexicano contemporáneo. Ficción, México, Cineteca Nacional.

Paz, Rafael (2013), "Heli es una película que no van a olvidar: Amat Escalante", en Forbes México, 9 de agosto de 2013, México, disponible en: https://www.forbes.com.mx/helies-una-pelicula-que-no-van-a-olvidar-amat-escalante/

Torres San Martín, Patricia (2008), "La recepción del cine mexicano y las construcciones de género. ¿Formación de una audiencia nacional?", La Ventana, vol. 3, núm. 27, pp. 58-103.

Zamorano Rojas, Alma Delia (2013), "Asesinos por naturaleza: una lectura primigenia de la violencia en el cine", Andamios, vol. 10, núm. 22, pp. 259-282.

Zimbardo, Philip (2018), El efecto Lucifer, México, Paidós.

Žižek, Slavoj (2009), Sobre la violencia. Seis reflexiones marginales, Barcelona, Paidós.

Žižek, Slavoj (2014), Acontecimiento, Madrid, Sexto Piso. 


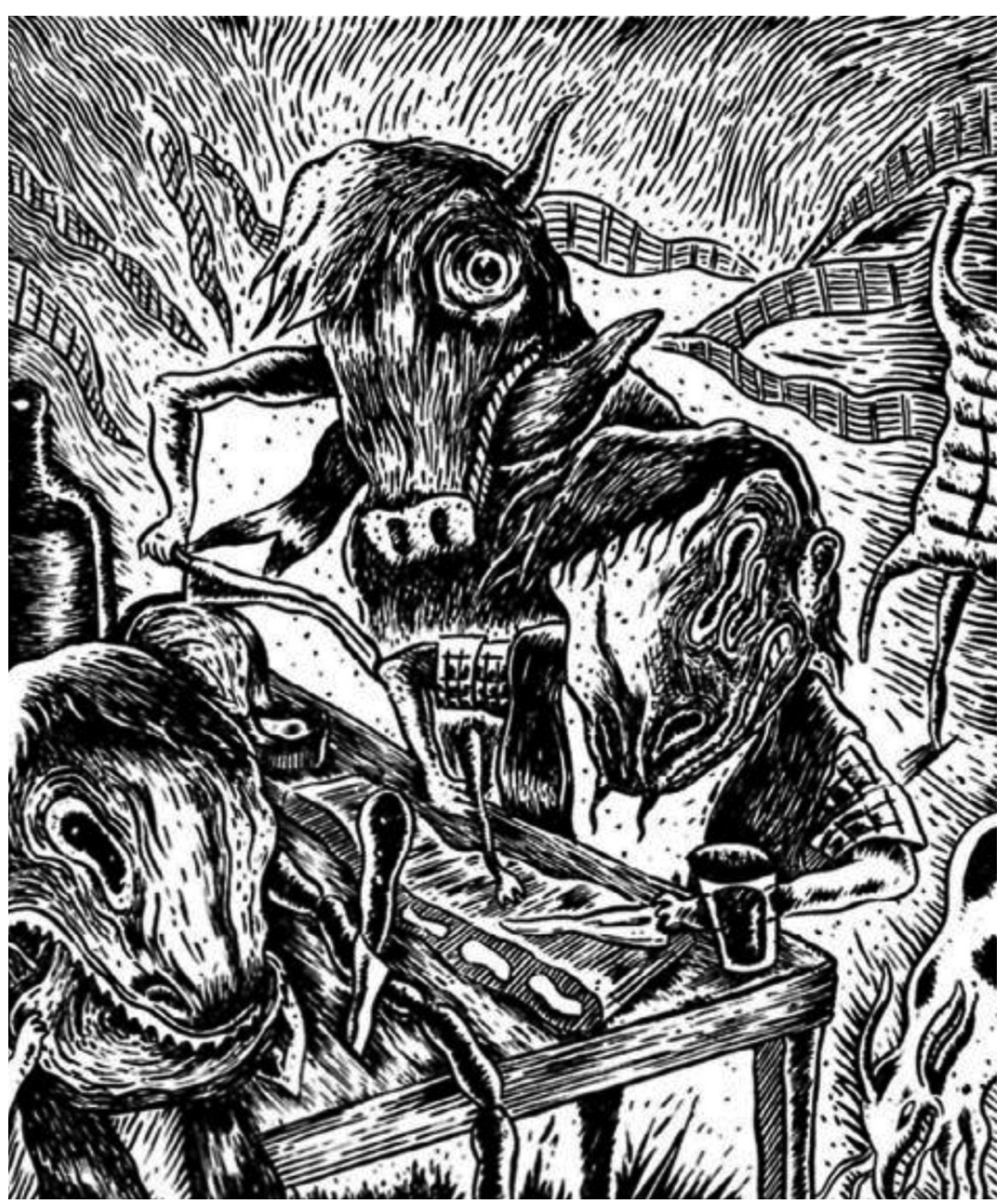

Viñeta de adaptación de El matadero, Suplemento Grueso Picado de la revista Fierro (2006). Tinta con Pluma y pincel : Juan Soto. Prohibida su reproducción en obras derivadas.

Juan Carlos Reyes Vázquez. Doctor en Teorías de la Creación y la Cultura, Maestro en Lengua y Literatura Hispanoamericana, Licenciado en Ciencias de la Comunicación. Miembro del Sistema Nacional de Investigadores en México (SIN). Actualmente, es profesor asociado e Investigador del Departamento de Ciencias de la Comunicación de la Universidad de las Américas Puebla (UDLAP), México. Sus líneas de investigación son: narrativa cinematográfica y literaria, estudios culturales, estudios visuales y de representación, y cultura digital. Ha publicado trabajos académicos, textos de divulgación, varios capítulos de libros, libros y reseñas. Ha sido becario de Conacyt, CONACULTA y Fonca. Como creador, ha dirigido y escrito más de diez cortometrajes que han viajado a festivales nacionales e internacionales como selección oficial en competencia. Algunos de ellos son Marble Tennis and Sky (2021), Absoluto vacío ensordecedor (2021), Acaso silencio (2018), Así comienza una montaña (2015), Silla eléctrica para moscas (2010), Barro (2009), y Lo demás es olvido (2005). También ha realizado la música o el guion de varios cortometrajes. Es autor de los libros de narrativa Imagínate lejos (2002), Circo de pulgas (2010), Iktumbe (2013), Para subir y caer (2015), e Impala (2021). 